\title{
Seismic Assessment and Retrofitting Of Damaged Quarry Stone Buildings in Nepal
}

\author{
Simon Mühlbauer, Dimitris Diamantidis ${ }^{2}$, Josef Schneider ${ }^{2}$ \\ ${ }^{1}$ Technical University Munich \\ Arcisstr. 21, Munich, Germany \\ simon.muehlbauer@tum.de; dimitris.diamantidis@oth-regensburg.de \\ ${ }^{2} \mathrm{OTH}$ Regensburg \\ Galgenbergstr. 30, Regensburg, Germany \\ schneider@schneider-bauing.de
}

\section{Extended Abstract}

The scope of this contribution is to provide and analyse a rehabilitation concept for typical brick residential buildings in Nepal damaged after the spring 2015 earthquake of magnitude 7.8. Development workers of Engineers Without Borders Germany travelled the same year to the village of Lurpung, southeast of Kathmandu to inspect damages and recommended primary approaches for the earthquake-resistant reconstruction of residential buildings [1].

A detailed restructuring concept is developed herein based on the aforementioned recommended approaches and optimized in terms of time and cost based on information reflecting site conditions and experience. For this purpose, a horizontal timber bracing has been designed, which consists to a large extent of local existing materials. It is demonstrated that the strengthening can be applied in an area of high seismic activity and to simple quarry stone masonry buildings typical for Nepal.

In a first stage, a detailed FE-model was developed, focusing on a realistic load-bearing behaviour of a representative typical structure. Thereby it is ensured that the most accurate internal forces and stresses can be obtained from the FEM analyses for further verification and retrofitting. Following the modelling, the equivalent static horizontal forces as a result of the relevant response spectrum are generated using the FE-software. Based on this procedure and with reference to Eurocode EN 1995 [2] for timber structures, the bracing system has been dimensioned for the maximum normal force resulting from the earthquake with a return period of 225 years corresponding to a peak ground acceleration of $0.35 \mathrm{~g}$. The considered earthquake reflects the regional seismicity described herein by a respective response spectrum with regard to the seismic provisions of Eurocode EN 1998 [3]. The reduced return period of 225 years compared to 475 years applied in design is selected in order to reflect a more reluctant safety target for existing structures [4]. The respective seismic hazard analysis is taken from Pradhan [5] and Chaulagain [6] and represents site specific conditions.

The improvement of the overall load-bearing behaviour influenced by the bracing, is subsequently checked by verifying the masonry walls using the Eurocode for masonry EN 1996 [7]. The material resistance parameters are taken from local studies and related testing outcomes [8]. The obtained structural analysis results show that wall shear capacity is utilized up to a ratio of $65 \%$ and the wall bending capacity is exceeded by $72 \%$. However, when compared with the original building, it can be determined that the mutual floor displacements can be reduced by a factor of up to 4.3 due to the proposed bracing system. Consequently, further retrofitting measures are recommended for the masonry. In that respect lower reliability levels can be of interest since a "discount" in the safety requirements for existing structures, however by fulfilling acceptable human safety levels, is usually unavoidable due to economical constraints.

The contribution leads to the conclusion that by retaining the static replacement system in the form of a truss, but adapting the building materials used, the basic functionality of the examined system can be provided. Although the FEM calculations have demonstrated satisfactory results further experimental campaigns are necessary to define the material properties of the considered typical building structures with respect to the analysed failure modes. The proposed approach supports efficient design of interventions in post-earthquake phases. 


\section{References}

[1] Engineers Without Borders Germany, intern documents. "Implementierung", 2017

[2] DIN EN 1995-1-1:2010-12, Eurocode_5: Bemessung und Konstruktion von Holzbauten_- Teil_1-1: Allgemeines_Allgemeine Regeln und Regeln für den Hochbau; Deutsche Fassung EN_1995-1-1:2004_+ AC:2006_+ A1:2008. Beuth Verlag GmbH, Berlin, 2010

[3] DIN EN 1998-1:2010-12, Eurocode_8: Auslegung von Bauwerken gegen Erdbeben_- Teil_1: Grundlagen, Erdbebeneinwirkungen und Regeln für Hochbauten; Deutsche Fassung EN_1998-1:2004_+ AC:2009. Beuth Verlag GmbH, Berlin, 2010

[4] D. Diamantidis, D., M. Holický and K. Jung, "Assessment of existing structures - on the applicability of the JCSS recommendations," in Aspects of Structural Reliability, in honor of Prof. Rackwitz, Herbert Utz Verlag, Munich, Germany, 2007

[5] P. Pradhan, "Construction of design response spectrum for Nepal: A probabilistic approach," University Grants Commission (UGC Nepal), 2020

[6] H. Chaulagain, H. Rodrigues, V. Silva, E. Spacone, "Seismic risk assessment and hazard mapping in Nepal," Nat Hazards, vol. 78, no. 1, pp. 583-602, 2015

[7] DIN EN 1996-1-1:2013-02, Eurocode_6: Bemessung und Konstruktion von Mauerwerksbauten_- Teil_1-1: Allgemeine Regeln für bewehrtes und unbewehrtes Mauerwerk; Deutsche Fassung EN_1996-1-1:2005+A1:2012. Beuth Verlag GmbH, Berlin, 2010

[8] R. Adhikari and D. D'Ayala, "2015 Nepal earthquake: seismic performance and post-earthquake reconstruction of stone in mud mortar masonry buildings," Bulletin of Earthquake Engineering, vol. 18, no. 8, pp. 3863-3896, 2020 